\title{
Do Academic Stress, Burnout and Problematic Internet Use Affect Perceived Learning? Evidence from India during the COVID-19 Pandemic
}

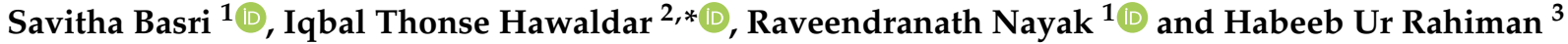 \\ 1 Manipal Institute of Management, Manipal Academy of Higher Education, Manipal 576104, India; \\ savitha.bs@manipal.edu (S.B.); ravi.nayak@manipal.edu (R.N.) \\ 2 Department of Accounting \& Finance, College of Business Administration, Kingdom University, \\ Riffa 40434, Bahrain \\ 3 Department of Finance \& Banking, College of Business Administration, Kingdom University, \\ Riffa 40434, Bahrain; h.rahiman@ku.edu.bh \\ * Correspondence: i.hawaldar@ku.edu.bh
}

check for

updates

Citation: Basri, S.; Hawaldar, I.T.;

Nayak, R.; Rahiman, H.U. Do

Academic Stress, Burnout and Problematic Internet Use Affect Perceived Learning? Evidence from India during the COVID-19

Pandemic. Sustainability 2022, 14,

1409. https://doi.org/10.3390/

su14031409

Academic Editor:

Jesús-Nicasio García-Sánchez

Received: 15 December 2021

Accepted: 20 January 2022

Published: 26 January 2022

Publisher's Note: MDPI stays neutral with regard to jurisdictional claims in published maps and institutional affiliations.

Copyright: (c) 2022 by the authors Licensee MDPI, Basel, Switzerland. This article is an open access article distributed under the terms and conditions of the Creative Commons Attribution (CC BY) license (https:/ / creativecommons.org/licenses/by/ $4.0 /)$.

\begin{abstract}
Distress in online classrooms and problematic internet use are two issues that have caused student burnout and affect perceived learning during the COVID-19 pandemic. Given the high pressure placed on students throughout COVID-19, it is critical to understand the influence of problematic internet use (PIU), psychological stress, academic burnout, and resilience on perceived learning (PL). A cross-sectional analytical study was chosen to collect data from 350 learners pursuing undergraduate and postgraduate business/management degrees in Karnataka, India. The data were analyzed using SPSS (Statistical Package for Social Science) and Smart PLS 3. The present study reports a non-significant negative total effect of stress on PL, while there was a significant positive direct effect but a significant indirect negative effect of multiple mediators, namely PIU, burnout, and resilience. In the relationship between stress and PL, burnout has full competitive mediation, and the suppressive effect of burnout and resilience wipes out the beneficial benefit of stress on PL, resulting in reduced PL. As a societal problem, a change in educational policy and prevention strategies for students and organizations (reducing the number of courses, number of exams, and handling parental expectations) would be effective. Emotional intelligence to improve resilience, which assists students in sailing through a current challenging situation and using IT for reducing negative and unexpected emotional outbursts should be encouraged.
\end{abstract}

Keywords: academic burnout; problematic internet use; stress; emergency remote teaching and learning; COVID-19; resilience

\section{Introduction}

Several countries, including India, resorted to the imposition of nationwide lockdown as a means of curtailing the spread of the novel coronavirus 2019. As a result, many businesses, sports and entertainment facilities, hospitality, and educational institutions were physically closed. Although digital migration in higher education is a recent phenomenon where Information and Communications Technology (ICT) has been applied in classroom delivery, assessment tasks, and conducting examinations using e-Pads, it was rapidly adopted during the pandemic with externally assisted migration online platforms such as Microsoft Teams, Zoom, GoToMeeting, Google Meet, and RingCentral video [1]. However, a successful transformation to emergency remote teaching and learning (ERTL) requires a focus on learner-centered pedagogy used in a climate of empathy and care $[2,3]$. Online curriculum transactions put pressure on students to adopt newer instructional methods and virtual interactions in online classrooms, online submission of assignments and tests, and minimize face-to-face interactions with instructors and peers [4,5]. If students lack 
digital competence and skills, an increase in academic stress levels and continuous pressure to be tech savvy produces burnout in ERTL environment [2,3]. Recent studies have shown a positive relationship between the mental wellbeing of students and higher academic achievement [6,7]. Because academic achievement influences a student's ability to obtain a rewarding career, advance in their profession, or be accepted into further education programs, as well as measures the skills of students in meeting specific learning objectives, higher education institutions must ensure that the negative impact of burnout on academic performance is addressed by promoting students' mental health during COVID-19 times [1]. Most studies focus on academic success or achievement, not students' perception of their learning. In this regard, perceived learning (PL), student's perspective of what they have learned, or deep learning, and not results measured in grades, can be used as a measure of academic success that emphasizes in-depth understanding of the courses being taught rather than superficial understanding [8-10]. As a metric for student outcomes, PL expresses students' impressions of their learning rather than learning as indicated by in-class evaluations [11].

In the ERTL environment, psychological well-being has attracted less attention as a public health concern even though it harms students who do not adopt non-optimal coping techniques [12-15]. A link between burnout and academic achievement has been established through psychological mechanisms of stress and problematic use of the Internet (PIU) $[16,17]$. Social isolation also prompts students to use various internet applications, social networking sites, and thus, internet use has increased to the point of making it difficult to concentrate on academics [1]. Students, on the other hand, can protect themselves from the negative effects of PIU and burnout on academic performance to a great extent if they develop positive coping techniques such as resilience and self-regulation [18]. Learners who self-regulate their learning and adopt cognitive and metacognitive strategies find the new environment favorable for learning [19].

Considering the substantial pressure imposed on students during COVID-19, an understanding of PIU, psychological stress, and burnout among students is necessary when trying to improve learning outcomes. There are few studies on students' perceived learning during the pandemic, while there is enough empirical evidence on academic achievement [20-25]. The effect of stress, PIU, and burnout on PL has not been addressed so far; therefore, this study was carried out in the Indian higher education context focusing on management and commerce students who were attending online classes during the lockdown. In the present study, we aim to explicate the relationship between perceived stress and PL, and multiple mediations of PIU, burnout, and resilience on PL. Burnout contributes significantly to diminished academic achievement; however, the role of resilience in positively influencing academic success when a student experiences burnout is less studied. Therefore, early recognition and treatment of burnout symptoms would prevent anxiety and study pressure and improve learning outcomes. An understanding of academic stress would be useful not only for suggesting student-related policies that would enhance learning while reducing burnout and PIU but also developing strategies to improve resilience to handle stressful situations.

\section{Literature}

Conservation of resource theory (CRT) explains the process of burnout and chronic stress and focuses on the circumstances under which people develop stress and react to stress in different ways [26]. During times of psychological or physical overload, the feeling of loss of resources accelerates, resulting in burnout, which usually occurs due to physical exhaustion or overload $[27,28]$. The Job Demands-Resources (JD-R) model proposed by Bakker and Demerouti [29] states that a mismatch between resources to fulfill job demands and the job requirements gives rise to stress. Learners with lower level of personal resources (coping mechanisms) would respond less effectively to study demands (Onwezen et al., 2012). Few studies probing students' reaction to transition to ERTL during the COVID-19 pandemic observe disruption of students' lives and increased 
stress and loneliness among students [30-33]. Since there are limited studies on perceived learning, the present paper has derived hypotheses from the literature on academic achievement. Burnout has been defined as a psychological syndrome that involves a prolonged response to stressors on academic work [34]. These negative emotional and psychological experiences would dampen students' enthusiasm to pursue learning and severely affect academic performance or learning [35]. Few studies explain variance in academic achievement or PL due to procrastination, anxiety, stress, absenteeism, insomnia, and internet addiction $[20,21,36]$. The three dimensions of academic burnout are emotional exhaustion, depersonalization, and academic inefficacy, during which students do not actively participate in classroom activities, lack interest in lessons and abstain from discussions in online classrooms [35,37-39]. Emotional exhaustion intensifies fatigue, irritability, frustration, or worn-out sensation and the students experiencing these would have a poor academic achievement [35]. The next level is depersonalization where they treat people as objects and become insensitive and cynical. Inefficacy results when a person feels lower personal accomplishment feels incompetent and evaluates oneself negatively [40,41]. A negative perception of one's inefficacy in completing academic tasks coupled with an inability and unwillingness to put in efforts [42] inhibits academic performance [20,22,23]. The Maslach Burnout Inventory-Student Survey Scale (MBI-SS) was developed, which focuses on unique conditions existing in the academic environment [42]. The MBI-SS has subscales of emotional exhaustion measuring study-related fatigue, cynicism assessing personal indifference towards studies, and professional inefficacy evaluating non-social and social features of accomplishment. The research studies on the relationship between burnout and academic achievement using the MBI-SS provide mixed results, both in magnitude and direction of relations. Few studies indicate a negative association between exhaustion and academic achievement [23,43,44]. Another study by Salanova et al. [45] revealed the poor academic performance of students suffering from burnout because of fatigue, irritability, frustration, detachment, and pessimism about academic activities. Several studies have pointed at a higher level of burnout among university students during the outbreak of the COVID-19 [46,47] and excessive use of social media giving rise to psychological issues [48-52]. Resilience not only improves wellbeing, but also reduces burnout and departure intentions $[39,53,54]$. Frustrated students failing to meet expectations or without coping strategies would develop apathy towards their studies and eventually burn out. In extreme cases, a lack of resilience may lead to departure from the program and turnout of students [39]. Several studies have shown a negative association between resilience and academic burnout [39,53-56]. Resilience reduces the harmful outcome of stressors on students' performance [57-59]. Students with strong resilience will be able to cope with burnout and stress, as well as bounce back after setbacks, by taking control of their lives $[31,57,58]$. Stress and burnout are mediated by resilience [60]. When students are constantly exposed to stressors, they develop a lack of resilience, which leads to burnout. Therefore, we hypothesize that:

Hypothesis 1 (H1). Academic burnout negatively influences PL.

Hypothesis 2 (H2). Resilience mediates the relationship between burnout and PL.

Hypothesis 3 (H3). Resilience positively affects PL.

In comparison to the public, perceived stress is higher among students and the consequent burnout has been observed in academic contexts [55,61,62]. Students in higher education institutions face intense stress about academic success that determines their career and placement opportunities. Burning out, depletion of one's resources results from prolonged stress; thus, burnout and stress are different not in terms of symptoms but due to the time involved in the process of its development [63]. Of these, stress contributed by going to classes, taking exams, searching for meaningful jobs, and participating in cocurricular and extra-curricular activities is one of the crucial determinants of burnout [35]. 
An academic track record would be adversely affected by cumulative stress and give rise to burnout, a syndrome with worrisome consequences [22,64,65]. Few studies have corroborated the negative effect of stressors and burnout on academic failure resulting in procrastination and departure from studies $[24,25,66]$. Therefore, the quality of life of students heavily relies on their ability to handle a range of study-related demands. Any failure to meet these demands and lack of resilience would impair mental health-giving rise to burnout $[67,68]$. Some studies have proven that coping with stressful events and destructive emotions such as stress and burnout is influenced by resilience, a psychological capital $[56,69,70]$. When students consume psychological resources continuously during the online classes, even if it is a low level of stress, they would experience burnout $[29,71]$. When stress is considered as an individual's incapacity to adjust to his/her environment, resilient people may mobilize all available resources to deal with it healthily $[33,58]$. Therefore, a study identifying the stress dimensions, namely pressure to perform, workload, and time restraints that affect burnout is required to suggest effective interventions to prevent and reduce burnout in students. Based on these inputs, we hypothesize that,

Hypothesis 4 (H4). Academic stress influences PL.

Hypothesis 5 (H5). Academic stress directly affects burnout.

Hypothesis 6 (H6). Academic stress has a positive relationship with resilience.

Young people have been observed to suffer from social, academic, and psychological problems due to PIU. Social isolation was observed to be the main determinant of PIU and not psychopathology of an individual [72] and thus, the term 'pathological internet use' must be replaced with 'problematic internet use'. PIU is defined by Beard and Wolf [73] as the excessive use of the Internet as a coping mechanism or a dysfunctional technique for dealing with stressful circumstances or loneliness, and few scholars have identified a higher level of PIU during the COVID-19 pandemic [51,74,75]. The online presence and lack of physical access to teachers and classmates may create psychological disturbances leading to PIU. Since frustrations, failures, disappointments, and stress in real life and family, social or college life relationships increases the likelihood of PIU as an escape route, PIU acts as an escape mechanism for stress associated with ERTL and provides a pseudo-cushion in which students feel that they control everything, but they might not cope with real problems [76]. As a result of repeated exposure to distressing news regarding the COVID-19 pandemic and deaths related to it, PIU heightens the likelihood of psychological maladjustment, leading to negative psychological consequences such as burnout, sleep difficulties, and depression [65,77-83]. Could PIU adversely affect learning and burnout when students are expected to access course materials as well as engage with peers and teachers in virtual classrooms? Further research into the impact of PIU on burnout and subsequent learning is required. Stay-at-home mandates promote social isolation, which leads to emotional instability and stress, which may result in PIU, which has a negative impact on psychological well-being, including loneliness, depression, anxiety, and burnout [84-87]. Thus, we hypothesize that

Hypothesis 7 (H7). Academic stress directly affects PIU.

Hypothesis 8 (H8). A higher level of PIU is associated with a greater level of burnout.

\section{Materials and Methods}

A cross-sectional analytical study was chosen to collect data from sample respondents at a point in time. The data were collected from learners pursuing undergraduate and postgraduate business/management degrees. Each of the selected institutions was affiliated with universities or departments of universities. Final-year students were chosen owing to 
their course load, prolonged exposure to online classes, curricula focusing on specialties requiring rigorous academic work, intense lecture sessions, and placement pressures. The students were briefed in the invitation email/message about the objectives of the study and the confidentiality of their information provided for the study. In applying the statistical techniques, Statistical Package for Social Science (SPSS) 24.0 and Smart PLS 3.0 (partial least square) was used. PLS-SEM is used when the sample size is small, and it requires fewer assumptions on data properties such as normality and heterogeneity.

The measurement model was assessed for reliability and validity for each construct and the items of the scale (internal consistency reliability and convergent and discriminate validity). Later, the structural model that shows the relationships among the constructs was estimated. The current study adopted a reflective-reflective type of model. The outer loadings of indicators signify the absolute contributions of indicators, and the threshold value of outer loadings is 0.70. Average variants extracted (AVE) is used to measure convergent validity, the commonality of a given construct. It is measured by finding out the average of the squared outer loadings of all indicators of a construct. Heterotrait-Monotrait Ratio of Correlations (HTMT) measures discriminant validity, which should be less than 0.9. The Variance Accounted For (VAF) value was calculated to know the level of mediation using the following formula: VAF = Indirect Effect/Total Effect. A value of less than 20\% denotes no mediation, $20-80 \%$ indicates partial mediation and more than $80 \%$ suggests full mediation. When the direct and indirect effects point in opposite directions, a competitive mediation arises [88].

\subsection{Measurement Tools}

A structured questionnaire was used to collect data on PIU, academic stress, burnout, resilience, and perceived learning. The established scales in the literature were used for this study. Burnout was measured using the MBI-SS scale that consisted of a 5-item emotional exhaustion subscale, 4-item depersonalization subscale, and 6-item diminished personal accomplishment subscale [38]. Cronbach's coefficient alpha was in the acceptable range for overall burnout (0.923), emotional exhaustion (0.853), cynicism (0.834), and inefficacy (0.881). The perceived stress scale again had three dimensions: 4 items on pressure to perform, 3 items on workload, and 3 items on a time restraint. The scale was adopted from Bedewy and Gabriel [89] and Cronbach's alpha reliability value was found to be satisfactory $(0.62,0.782$, and 0.613 , respectively). Resilience was measured by using the validated Connor-Davidson Resilience Scale [90] which has 10 items, but only seven items related to academic resilience were used for this study. The scale demonstrated modestly satisfactory internal consistency, with a Cronbach's alpha of 0.875 . These scales were measured on a 5-point Likert scale (1, strongly disagree; 5 strongly agree). PIU was measured using a scale developed by Young and Rogers [36] and each item was measured on a 5-point scale, ranging from 1 (never) to 5 (always) for each subscale (Cronbach's alpha 0.820). Perceived learning was measured using the scale of Rovai et al. [9] (Cronbach's alpha of 0.614) (Appendix A). Structural equation modeling was used to explain variation in the perceived learning of students. The Partial Least Squares (PLS) is quite popular owing to the small sample size for complex models and few assumptions on data properties such as normality and heterogeneity.

\subsection{Sampling Design}

The population for the study was students of business management and commerce institutions and the sampling frame was the list of students that were accessible in the randomly selected ten colleges (out of 24 colleges) who were pursuing undergraduate (UG) and postgraduate (PG) education in various institutions in Coastal Karnataka. Each institution had around 200 UG students and 120 PG students. Therefore, the sample frame was 3200. However, we approached only final year students, comprising a total of 1200 . A total of 350 students were requested to fill out the questionnaire over 3 months (September to November 2020). In the absence of an accessible sampling frame, especially 
during the current pandemic, when physical movements were restricted, the exponential non-discriminatory snowball sampling method was used to collect the data. A small group of students pursuing undergraduate or postgraduate degrees were first selected, and then they were asked to suggest potential subjects to whom questionnaires were sent in the next stage and so on until the required sample was obtained. The survey instrument was administered using online applications such as WhatsApp, emails, and social media.

\section{Results}

The sample consisted of $54.8 \%$ males and $45.2 \%$ females, with ages ranging from 21 to 27 years. The majority were 21 to 25 years old $(91.8 \%)$ and $44.1 \%$ lived in urban areas, while $31.2 \%$ were in rural and the remaining were in semi-urban areas. All constructs had a lower than five variance inflation factor (VIF) value and all the indicators were reflective; hence, the statistical significance of independent variables would not be affected by multi-collinearity.

\subsection{Assessment of Measurement Model}

The indicators of many constructs demonstrate higher outer loadings than the threshold value of 0.70 and composite reliability values were above 0.85 , much above the threshold value of 0.7 (Table 1 ).

Table 1. Reliability and convergent validity.

\begin{tabular}{|c|c|c|c|c|}
\hline Construct & Indicators & Outer Loadings & $\begin{array}{l}\text { Composite } \\
\text { Reliability }\end{array}$ & AVE \\
\hline \multirow{3}{*}{ Problematic Internet Use } & PIU1 & 0.822 & \multirow{3}{*}{0.850} & \multirow{3}{*}{0.655} \\
\hline & PIU2 & 0.821 & & \\
\hline & PIU3 & 0.784 & & \\
\hline \multirow{4}{*}{ Perceived stress } & S1 & 0.829 & \multirow{4}{*}{0.880} & \multirow{4}{*}{0.647} \\
\hline & S2 & 0.838 & & \\
\hline & S3 & 0.792 & & \\
\hline & S3 & 0.758 & & \\
\hline \multirow{3}{*}{ Cynicism } & $\mathrm{C} 1$ & 0.859 & \multirow{3}{*}{0.889} & \multirow{3}{*}{0.669} \\
\hline & $\mathrm{C} 2$ & 0.870 & & \\
\hline & $\mathrm{C} 3$ & 0.818 & & \\
\hline \multirow{4}{*}{ Exhaustion } & E1 & 0.761 & \multirow{4}{*}{0.901} & \multirow{4}{*}{0.696} \\
\hline & E2 & 0.843 & & \\
\hline & E3 & 0.837 & & \\
\hline & E4 & 0.891 & & \\
\hline \multirow{6}{*}{ Inefficacy } & IE1 & 0.787 & \multirow{6}{*}{0.909} & \multirow{6}{*}{0.625} \\
\hline & IE2 & 0.838 & & \\
\hline & IE3 & 0.825 & & \\
\hline & IE4 & 0.740 & & \\
\hline & IE5 & 0.817 & & \\
\hline & IE6 & 0.729 & & \\
\hline
\end{tabular}


Table 1. Cont.

\begin{tabular}{|c|c|c|c|c|}
\hline Construct & Indicators & Outer Loadings & $\begin{array}{l}\text { Composite } \\
\text { Reliability }\end{array}$ & AVE \\
\hline \multirow{6}{*}{ Resilience } & RS1 & 0.783 & \multirow{6}{*}{0.911} & \multirow{6}{*}{0.632} \\
\hline & RS2 & 0.847 & & \\
\hline & RS3 & 0.896 & & \\
\hline & RS4 & 0.723 & & \\
\hline & RS5 & 0.743 & & \\
\hline & RS6 & 0.766 & & \\
\hline \multirow{4}{*}{ Perceived Learning } & L1 & 0.823 & \multirow{4}{*}{0.899} & \multirow{4}{*}{0.689} \\
\hline & L2 & 0.807 & & \\
\hline & L3 & 0.864 & & \\
\hline & L4 & 0.825 & & \\
\hline
\end{tabular}

Note: AVE-Average Variance Extracted.

Average variance extracted (AVE) to measure convergent validity was found to be above 0.5 , which implies that a given construct can explain more than half of its indicators' variances (Table 1). The HTML ratio criterion that measures discriminant validity was less than the cut-off 0.9 value (Table 2 ).

Table 2. Discriminant Validity: HTMT.

\begin{tabular}{ccccccc}
\hline & Cynicism & Exhaustion & Inefficacy & $\begin{array}{c}\text { Problematic } \\
\text { Internet Use }\end{array}$ & PL & Resilience \\
\hline Cynicism & - & - & - & - & - & - \\
\hline Exhaustion & 0.737 & - & - & - & - & - \\
\hline Inefficacy & 0.763 & 0.726 & - & - & - & - \\
\hline $\begin{array}{c}\text { Problematic } \\
\text { Internet Use }\end{array}$ & 0.573 & 0.497 & 0.638 & - & - & - \\
\hline $\begin{array}{c}\text { Perceived } \\
\text { learning }\end{array}$ & 0.394 & 0.281 & 0.469 & 0.213 & - & - \\
\hline Resilience & 0.416 & 0.338 & 0.381 & 0.357 & 0.759 & - \\
\hline Stress & 0.530 & 0.613 & 0.615 & 0.563 & 0.159 & 0.308 \\
\hline
\end{tabular}

HTMT—Heterotrait-monotrait ratio of correlations; PL—Perceived Learning.

\subsection{Structural Model: Estimating the Model without First-Order Constructs}

The three components of burnout, namely exhaustion, cynicism, and inefficacy, were considered as separate constructs in the first-order model, and the overloading and measurement model was assessed for its reliability and validity. After establishing the relevance of the measurement model, the second-order model where burnout was measured as a formative construct was formed by the three reflective first-order constructs (reflectiveformative model). The latent scores of the three lower-order constructs of burnout were added to the dataset before running stage two. Here, the three latent variable constructs acted as the indicators of the higher-order construct burnout forming it. In the measurement model of the formative higher-order construct (HOC), burnout was validated by running the bootstrapping procedure with 5000 samples. The outer weights were checked for significance, and here the outer weight of exhaustion, cynicism, and inefficacy was above 0.5 and were significant.

There are four exogenous constructs, including stress influencing PIU and burnout, which in turn affect PL. Resilience moderates the relationship between burnout, stress, PIU, and PL. The $R^{2}$ of PL and burnout was moderately high at 0.489 and 0.431 , respectively, 
suggesting that our structural model has good predictive validity. The $\mathrm{R}^{2}$ of PIU was 0.198 and resilience was 0.135 , indicating a lower predictive ability. The significant path coefficients imply a strong positive relationship between PL and burnout $(\beta=-0.31, p<0.00)$ (H1), stress and PL $(\beta=0.21, p<0.05)(\mathrm{H} 2)$, burnout and PIU $(\beta=0.35, p<0.00)$, stress and burnout $(\beta=0.43, p<0.00)(\mathrm{H} 4)$, stress and PIU $(\beta=0.45, p<0.00)(\mathrm{H} 3)$, resilience and PL $(\beta=0.64, p<0.00)$, and resilience and burnout $(\beta=-0.36, p<0.00)$.

Multiple mediation effects were assessed. The strengths of mediation effects using variance accounted for (VAF) is depicted in Table 3. The specific indirect effects (partial complementary) of burnout in mediating the relationship between stress and PL ( $\beta=-0.14$, $p<0.001$ ) were seen (Table 4 ). Furthermore, the partial complementary indirect effect of Stress - > PIU - > Burnout $(\beta=0.14, p<0.001)$, Stress $->$ Burnout $->$ Resilience $->$ PL $(\beta=-0.11, p<0.05)$ Stress $->$ PIU $->$ Burnout $->$ Resilience $(\beta=-0.05, p<0.05)$, and Stress - > Burnout - $>$ Resilience $(\beta=-0.17, p<0.05)$ was observed. Moreover, PIU $->$ Burnout - $>$ Resilience - $>$ PL $(\beta=-0.07, p<0.05)$, PIU $->$ Burnout $->$ Resilience $(\beta=-0.11$, $p<0.001)$, PIU $->$ Burnout $->$ PL $(\beta=-0.09, p<0.001)$, and Burnout $->$ Resilience $->$ PL $(\beta=-0.23, p<0.001)$ were noted. Partial competitive indirect effect was observed in the path Stress - $>$ PIU - > Burnout - $>$ PL $(\beta=-0.04, p<0.001)$ and Stress - $>$ PIU $->$ Burnout $>$ Resilience $->$ PL $(\beta=-0.03, p<0.05)$, For the first-order model, the bootstrap-based exact fit measures, as well as approximate fit measures, such as SRMR indicate that model fits well, SRMR was 0.08 which less than 0.1 [40] and NFI (normed fit index) closer to 1 (0.721) and RMS_theta values of 0.117 (desirable value is less than 0.12 ) indicate a good fit model.

Table 3. Determinants of perceived learning: multiple mediation analysis.

\begin{tabular}{|c|c|c|c|c|c|}
\hline & $\begin{array}{c}\text { Specific } \\
\text { Indirect Effects }\end{array}$ & $\begin{array}{c}\text { Total } \\
\text { Effects }\end{array}$ & $\begin{array}{c}\text { Confidence Intervals } \\
\text { Bias Corrected } \\
25 \%: 97.5 \%\end{array}$ & VAF & Type of Mediation \\
\hline Stress - > PIU - > Burnout - > Resilience - > PL & $\begin{array}{l}-0.03 * * \\
(2.21)\end{array}$ & $\begin{array}{l}-0.08 \\
(0.72)\end{array}$ & $-0.06:-0.01$ & $37.5 \%$ & Partial competitive \\
\hline Stress - > Burnout - > Resilience $->$ PL & $\begin{array}{l}-0.10 * * \\
(2.55)\end{array}$ & $\begin{array}{l}-0.08 \\
(0.72)\end{array}$ & $-0.20:-0.03$ & $100 \%$ & Competitive \\
\hline Stress - > PIU - > Burnout & $\begin{array}{l}0.14 * \\
(3.39)\end{array}$ & $\begin{array}{l}0.60 * \\
(9.98)\end{array}$ & $0.06: 0.21$ & $23 \%$ & $\begin{array}{c}\text { Partial } \\
\text { complementary }\end{array}$ \\
\hline Stress - > Burnout - > PL & $\begin{array}{l}-0.14^{*} \\
(2.95)\end{array}$ & $\begin{array}{l}-0.08 \\
(0.72)\end{array}$ & $-0.23:-0.06$ & $100 \%$ & Competitive \\
\hline PIU - > Burnout - > PL & $\begin{array}{l}-0.09 * \\
(3.29)\end{array}$ & $\begin{array}{l}-0.16 * \\
(3.64)\end{array}$ & $-0.14:-0.04$ & $56 \%$ & $\begin{array}{c}\text { Partial } \\
\text { complementary }\end{array}$ \\
\hline Stress - > PIU - > Burnout - > Resilience & $\begin{array}{l}-0.05^{* *} \\
(2.44)\end{array}$ & $\begin{array}{l}-0.24^{* *} \\
(2.19)\end{array}$ & $-0.09:-0.02$ & $21 \%$ & $\begin{array}{c}\text { Partial } \\
\text { complementary }\end{array}$ \\
\hline Burnout - > Resilience - > PL & $\begin{array}{l}-0.23 * \\
(3.01)\end{array}$ & $\begin{array}{l}-0.51 * \\
(4.55)\end{array}$ & $-0.36:-0.05$ & $45 \%$ & $\begin{array}{c}\text { Partial } \\
\text { complementary }\end{array}$ \\
\hline Stress - > Burnout - > Resilience & $\begin{array}{l}-0.17 * * \\
(2.49)\end{array}$ & $\begin{array}{l}-0.25^{* *} \\
(2.19)\end{array}$ & $-0.33:-0.05$ & $68 \%$ & $\begin{array}{c}\text { Partial } \\
\text { complementary }\end{array}$ \\
\hline PIU - > Burnout - > Resilience - > PL & $\begin{array}{l}-0.07^{* *} \\
(2.53)\end{array}$ & $\begin{array}{l}-0.16 * \\
(3.64)\end{array}$ & $-0.13:-0.02$ & $44 \%$ & $\begin{array}{c}\text { Partial } \\
\text { complementary }\end{array}$ \\
\hline Stress - > PIU - > Burnout - > PL & $\begin{array}{l}-0.04 * \\
(2.85)\end{array}$ & $\begin{array}{l}-0.08 \\
(0.72)\end{array}$ & $-0.07:-0.02$ & $50 \%$ & Partial competitive \\
\hline Stress - > Resilience - > PL & $\begin{array}{l}-0.02 \\
(0.28)\end{array}$ & $\begin{array}{l}-0.08 \\
(0.72)\end{array}$ & $-0.16: 0.12$ & - & - \\
\hline
\end{tabular}

${ }^{*}$ PL-Perceived learning; ${ }^{* *}$ PIU—Problematic Internet Use; VAF-Variance Accounted For. 
Table 4. F2 and Q2 effect size results.

\begin{tabular}{cccccc}
\hline & Burnout & $\begin{array}{c}\text { Problematic } \\
\text { Internet Use }\end{array}$ & $\begin{array}{c}\text { Perceived } \\
\text { Learning }\end{array}$ & Resilience & $\begin{array}{c}\mathbf{q}^{\mathbf{2}} \text { Effect Size } \\
\text { (Predicting PL) }\end{array}$ \\
\hline Burnout & - & - & 0.101 & 0.100 & 0.113 \\
\hline $\begin{array}{c}\text { Problematic } \\
\text { Internet Use }\end{array}$ & 0.175 & - & 0.010 & - & 0.253 \\
\hline $\begin{array}{c}\text { Perceived } \\
\text { learning }\end{array}$ & - & - & - & - & - \\
\hline Resilience & - & - & 0.692 & - & 0.441 \\
\hline Stress & 0.262 & 0.260 & 0.058 & 0.002 & - \\
\hline PL-Perceived learning. & & & &
\end{tabular}

We have observed a suppression effect in which a non-significant total effect of stress on PL could be partitioned into a significant direct but positive effect and indirect negative significant effect, which cancel out each other (Figure 1). Because the inclusion of burnout, PIU, and resilience as the mediator decreases the positive effect of stress on PL, direct and indirect effects with opposite signs were observed. The full competitive mediation was evident as burnout mediated $(\beta=-0.14, p<0.00)$ the path between stress and PL, and multiple mediations of burnout and resilience in the relationship between stress and PL $(\beta=-0.10)$.

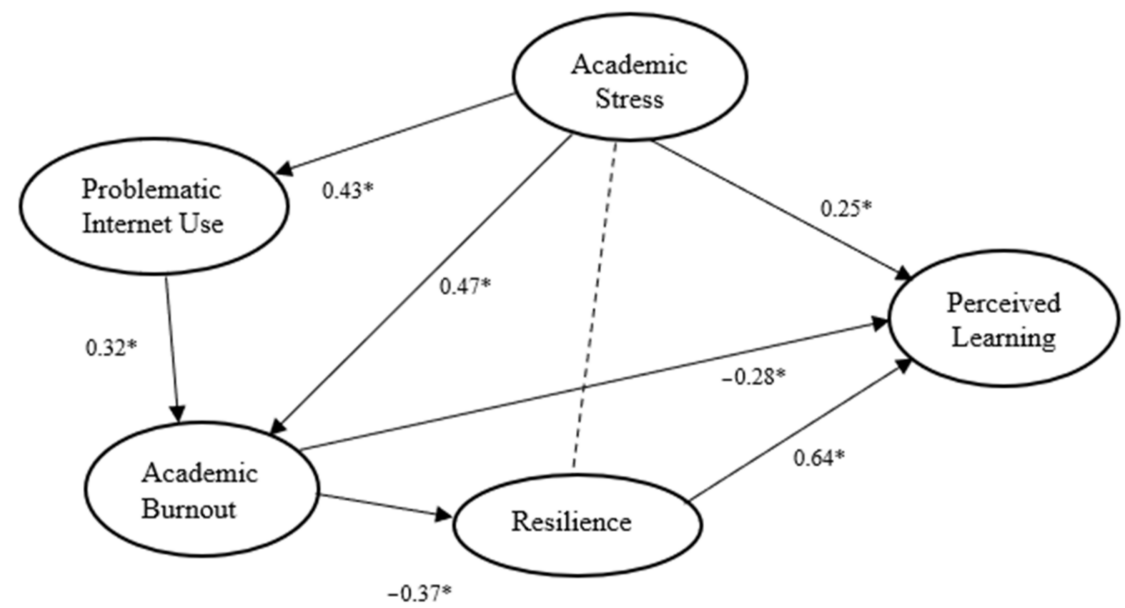

Figure 1. Structural Model Predicting Perceived Learning: Direct Effects. ${ }^{*} p<0.00,-$ denotes insignificant relationship.

The blindfolding procedure was carried out to assess predictive relevance. The model has a Q2 value of 0.312 , which is larger than zero; hence, the model has predictive relevance. The $\mathrm{f} 2$ analysis (Table 5) reveals that resilience - > PL has a value of 0.692 , suggesting a considerable significant effect, stress - > internet addiction has a value of 0.260 , PIU - > burnout has a value of 0.175 , and stress - > burnout has a value of 0.262 , which are mediumsize effects. Burnout and stress on PL have a small effect (less than 0.10). 
Table 5. Determinants of perceived learning: direct effects.

\begin{tabular}{ccccc}
\hline & $\begin{array}{c}\text { Path } \\
\text { Coefficient }\end{array}$ & $\begin{array}{c}\mathbf{t} \\
\text { Statistics }\end{array}$ & $p$ Values & Confidence * \\
\hline H1: Burnout - > PL & -0.28 & 3.61 & 0.00 & $-0.42:-0.12$ \\
\hline H2: Burnout - > Resilience & -0.37 & 2.96 & 0.00 & $-0.58:-0.11$ \\
\hline H3: Resilience - > PL & 0.32 & 4.78 & 0.00 & $0.16: 0.42$ \\
\hline H4: Stress - > PL & 0.64 & 9.03 & 0.00 & $0.48: 0.75$ \\
\hline H5: Stress - > Burnout & 0.47 & 7.52 & 0.00 & $0.33: 0.57$ \\
\hline H6: Stress - > Resilience & 0.43 & 4.93 & 0.00 & $0.24: 0.57$ \\
\hline H7: Stress - > PIU & 0.25 & 3.30 & 0.00 & $0.08: 0.37$ \\
\hline $\begin{array}{c}\text { H8: Problematic Internet } \\
\text { Use - > Burnout }\end{array}$ & -0.03 & 0.29 & 0.77 & $-0.26: 0.19$ \\
\hline${ }^{*}$ Intervals Bias Corrected 25\%: $97.5 \%$ & & & &
\end{tabular}

* Intervals Bias Corrected 25\%: 97.5\%.

\subsection{Importance-Performance Map Analysis (IPMA)}

IPMA analysis reveals that PIU has relatively greater importance $(-0.083)$ but lower performance (43.53) for resilience, whereas burnout and stress have lower importance $(-0.28$ and -0.22 , respectively) but higher performance (51.64 and 56.68, respectively). However, urgent actions are needed to reduce PIU as it seems to be an important determinant of resilience with a higher effect but lower performance. IPMA analysis for PL and burnout did not suggest any areas for immediate action (either construct being in the first quadrant implying that no action is needed or too much performance without much effect).

\section{Discussion}

The present study reports a non-significant negative total effect of stress on PL while a significant positive direct effect (stress - > PL) and a significant indirect negative effect of multiple mediators (stress $->$ PIU $->$ burnout $->$ resilience $->$ PL). The direct but positive effect of stress on learning (Table 5) implies that a certain level of stress is needed for effective learning. However, the indirect effect occurs when a higher level of stress leads to PIU, which in turn would not only cause burnout but also negatively affect perceived learning (Table 4). In the relationship between stress and PL, burnout has full competitive mediation, which means that a favorable effect of stress on PL becomes negative if stress leads to burnout and lower resilience. Thus, the suppressive effect of burnout and resilience cancels out the favorable impact of stress on PL, resulting in lower PL. The present study found no direct effect of stress on resilience but suppressing the mediating effect of burnout in reducing the resilience of students, implying that if stress causes burnout, the resilience capacity of learners would be negatively affected that hampers learning. The effect of stress on PL via PIU is less pronounced compared to the impact of stress on burnout and resilience, which in turn negatively affects PL. Moreover, PIU has a substantial negative impact on student resilience, which necessitates the attention of educators and parents.

Perceived stress arising out of the pandemic and lack of social interactions with higher online exposure puts pressure on students. When students feel exhausted and perceive themselves to be incompetent, the frustration or tension about academic performance forces them to engage in avoidance behaviors such as abstaining from classroom activities and being absent from the learning context. Thus, effective learning is diminished because of psychological and physical withdrawal from studies, which is commonly observed in students experiencing burnout $[20,35,37,44]$. Management is a stressful profession and learning new technical subjects and gaining competency requires a considerable amount of time and dedication which may take a toll on the students $[24,25,55]$. The study pressure, workload, and continuous stress would lead to PIU and academic burnout, and in the end, students may fail to develop any competencies. It is possible that when an individual faces a challenging situation such as ERTL when they are used to physical classroom teaching 
methods, they would feel unhappy or have a sense of lack of control and experience burnout. This is when the objectives set are too high to achieve with the capability of an individual, so they might feel ineffective to meet the performance standards. Therefore, feelings of powerlessness or uselessness increase emotional exhaustion, depersonalization, and inefficacy and reduce the level of psychological resilience, and thereby negatively affect academic learning as endorsed by few studies [35,38,45,63].

Since the onset of pandemic, most universities and educational environments have adopted an online mode of learning, and students are expected to complete assignments and projects and take tests online using ICT infrastructure and tools provided by institutions. Being online to undertake these tasks increases emotional exhaustion and lack of touch with real persons. Among the online activities, social networking, entertainment, and gaming activities have become a part of daily social life, as reported by some studies [48,50,51]. As an important means of communication, social networking is the main reason behind mental health issues. The intensive use of these sites causes psychological distress; accordingly, we found a direct effect of PIU during the pandemic and burnout experienced by the students. Similarly, many studies have observed a significant relationship between burnout and PIU caused by depression or stress $[66,76,80,81]$.

As internet penetration has improved, young adults have increased their use of social media sites such as Facebook, Instagram, and Twitter that have been integrated into their lives. Students addicted to the Internet experience a high level of distress and burnout; this finding has been observed in other studies [74,85-87]. However, the beneficial effect of the internet during online education in the form of constant communication with peers and teachers and the advantages of these communications and relationships during home isolation and social exclusion cannot be denied. The supportive function of internet platforms in improving interpersonal interactions also provides immense scope to surf the Internet for gaming, watching movies, or other distractive and harmful activities and hampers academic achievement. Excessive use of the Internet occurs when students have some difficulties in mastering the subject or face problems in understanding the curriculum. Stressful situations give rise to burnout and increase the likelihood of discontinuing their education and lead to failure when learners are deprived of classroom group activities and peer learning, physical sports activities, or social engagement. Without any support from educators or classmates in understanding difficult subjects or concepts, family-related pressures, competition among peers, financial distress, and academic prerequisites lead to academic burnout $[7,17,22]$.

Many studies have corroborated our findings of a negative relationship between academic burnout and academic success $[44,45]$. The findings of our study demonstrate that resilience is a key component in decreasing the impact of burnout on learning. It reduces negative psychological ill-health through its positive association with psychological health and thus improves academic outcomes. When students feel exhausted, irritable, detached, and cynical about study-related tasks, their dedication to academic work declines. Lack of energy and resources required to meet academic pressures and expectations makes students perform poorly. When learners face difficulties grasping technical concepts and lag others, the inability to excel as expected forms into a negative attitude towards academic tasks and they become indifferent (cynicism). A feeling of inadequacy and perception of reduced competence (inefficacy) leads to ineffective outcomes $[38,44]$. Since the students attend classes and carry out several structured activities to pass a course or earn a degree, academic exhaustion, cynicism related to study, and decreased efficacy to complete the assessment tasks can be expected. Few studies have reported the benefits of resilience $[39,45,57,90]$. Smith et al. [39] contend that students' capacity to cope (based on resilience level and mental health status) will decrease the negative consequences of stress on academic decisions. Disengagement with others because of spending most of their time on the Internet harms social relationships, causes burnout, and reduces resilience to cope with academic challenges. A perceived or real fear of internet disconnection or failure during time-bound assessment tests and exams also adds to the stress. Some 
students spread rumors that the end-of-semester or end-of -year exams can be cancelled unnecessarily distracts most of the students in that they participate willingly or unwillingly in mass letter campaigns to cancel the exams. The energy of the students is drained as the exams are nearing. When the exams are not cancelled, they are not ready psychologically to face the exams.

\section{Practical Implications}

Despite the beneficial effect of social networking on a person's development and communication with peers, specifically to those feeling socially excluded, it is useful to classify harmful and non-harmful activities and guide learners on their proper use. Therefore, internet education is highly needed to create awareness about the adverse effect on psychological health. Higher education institutions should frame guidelines and communicate with students of possible risks of harmful use of the Internet among students and encourage the efficient use of this technology to prevent risks including academic burnout. Educators can also incorporate variety into the curriculum to encourage students to collaborate and obtain skills through vocational certification, as well as foster inventiveness and coping abilities that will allow learners to develop resilience. Close monitoring by parents on the behavior of their children while attending online classes would reduce excessive internet activities. The importance of support from teachers, peers, and counseling must be acknowledged and these stakeholders should be a part of counselling process.

Higher education institutions should make clear the adverse implications of burnout among their faculty and students. As a societal problem, change in educational policy and prevention strategies for individuals (stress management) and organizations (reducing the number of courses, number of exams, handling parental expectations) is likely to be most effective $[5,10]$. We suggest students experiencing burnout should be asked to reduce the number of difficult courses and reduce extracurricular activities. Instead, a weekly schedule must be prepared to identify productive activities and focus on effective time management. Inefficacy beliefs make students disengage in academic tasks as they feel incompetent and lack confidence and spend less time and expend fewer efforts on academic activity. Students feeling efficacy would persevere, even if they faced obstacles, and be resilient in difficult situations. To tackle cynicism that shows a lack of empathy and a sense of community, civility interventions are to be imbibed among students. Emotional intelligence to improve resilience that assists students to sail through current challenging situation and the use of ICT for reducing negative and unexpected emotional outbursts should be encouraged.

The institutions should advise students to work less, reduce the number of contact hours and leave adequate breaks in between the class and avoid overloading the students with assignments in a particular period (say, the last few weeks of the semester); rather, these should be spread out throughout the semester. They should provide mechanisms and skills to cope with addiction and burnout, including cognitive restructuring, conflict resolution, time management, social support (both from teachers, peers, and family), and the use of relaxation strategies (online yoga classes). The educational institutions must fulfill confidence among the students in facing the proctored exams. Any internet issues they face during the exams are not set against them. Any fears about the proctored exams are to be allayed and post-exam disputes need to be resolved. Since performance in exams plays an important role in the success of students' lives and careers, any concerns in the minds of students in attending the exams in online mode (in particular, in proctored exams) need to be resolved by the institutions early on. The students should also be trained to develop a better understanding of themselves using various self-analytic techniques, counselling, or therapy. The lack of time and psychological stamina to withstand pressure prevents students from refining existing skills and learning new courses. The sense of inefficacy cripples the students' ability to perform. Inefficacy can be reduced by being responsive and recognizing changes in behavior such as prompt submission of assignments, completion of 
online certificate courses, active interaction in classrooms, positive contribution in group discussions, and peer interactions.

\section{Conclusions}

The current study found full suppression of the positive effect of stress on PL, giving rise to a negative non-significant effect on PL due to the combined negative profound effect of PIU, burnout, and lack of resilience. If stress causes PIU and prolonged stress transforms to burnout, there would be an adverse effect on student learning. We found a negative effect of burnout on resilience and PL, implying that academic burnout (cynicism, exhaustion, and inefficacy) decreases psychological flexibility to face academic challenges and thereby reduces learning. Long-term use of the internet as a stressbuster gives rise to burnout, which in turn reduces not only resilience but also perceived learning.

Online education poses challenges to students who lack independence and selfdirected learning motivation and self-regulation. The students experiencing stress feel exhausted, lack concern for others, feel incompetent in completing assignments and lack interest in writing examinations. The study-related pressure and burnout turn into poorquality project work, late submissions, and lower accomplishment of learning goals. On the other hand, students who had lower levels of stress developed strong beliefs that they would succeed, took responsibility for their learning, and used technology better. These students enjoy doing study-related tasks and feel less exhausted or depersonalized and have a higher level of self-efficacy; all these reduce stress, and thereby, burnout would be lesser. Therefore, they perform better than students with high burnout.

Given the negative impact of burnout on students' ability to cope with academic problems, higher education institutions must support students to maintain enthusiasm all through the program. Because students who have low resilience are often more prone to losing sight of their learning goals and the importance of mastering the subjects, they might eventually drop out of the program. Establishing a relationship of trust and a degree of comfort with students, increased engagement with the quiet students, and creating a sense of the course as a continuous joint effort can help to mitigate the harmful effects of stress on students. Rather than recreating the physical classroom in the virtual online environment, educational institutions should seek to maximize the potential of the digital environment whilst eliminating the challenges.

\section{Limitations and Future Scope for Research}

The contextual factors in other regions of the country would differ; thus, the socioeconomic backgrounds of students studying in other states of India and other countries can be studied in the future. The role of individual and institution-related factors in influencing stress and PIU can be studied in the future. Variations in the predictability of the model in different demographic groups can be studied. A description of the types of activities promoted under ERTL could not be included in the paper. Since this study is a correlation analysis, explanatory research exploring cause and effect relationships can be studied using longitudinal studies. Studies should also focus on the pathways to burnout and the moderating effect of personal, lifestyle, and social factors on the relationship between burnout and achievement. It is important to understand how instructor burnout influences student burnout and whether this affects academic achievement. Studies can be conducted that examine the destructive behavior of the section of the students who engage in sabotaging the holding of online tests. Furthermore, several alternatives but reliable assessment tasks should be developed that measure student learning in online classes using students from other areas of knowledge and monitoring the effect of different emergency remote teaching and learning practices would be very useful. 
Author Contributions: Conceptualization, S.B. and H.U.R.; methodology, S.B., I.T.H., R.N.; software, S.B.; validation, I.T.H., H.U.R., and S.B.; formal analysis, R.N. and H.U.R.; investigation, S.B. and R.N.; resources, I.T.H. and H.U.R.; data curation, S.B.; writing, S.B., I.T.H., R.N. and H.U.R.; writingreview and editing. H.U.R.; visualization, I.T.H., R.N. and H.U.R.; supervision, I.T.H.; R.N; project administration, S.B.; funding acquisition. All authors have read and agreed to the published version of the manuscript.

Funding: This research received no external funding.

Institutional Review Board Statement: Not applicable.

Informed Consent Statement: Not applicable.

Data Availability Statement: The data presented in this study are available on request from the corresponding author. The data are not publicly available due to privacy issues.

Acknowledgments: We appreciate all respondents for cooperating in the survey.

Conflicts of Interest: The authors declare no conflict of interest.

\title{
Appendix A. Measurement Scale
}

\author{
I feel emotionally drained by my studies. \\ I feel tired when I get up in the morning and I have to face another day \\ at the university. \\ Studying or attending a class is really a strain for me. \\ I feel burned out from my studies \\ I have become less enthusiastic about my studies. \\ Burnout I've become more cynical about the potential usefulness of my studies. \\ I doubt the significance of my studies. \\ I can't solve the problems that arise in my studies. \\ I believe that I don't make an effective contribution to the classes that I attend. \\ In my opinion, I am not a good student. \\ I don't feel stimulated when I reach my study goals. \\ I haven't learnt any interesting things during my studies. \\ During class I don't feel confident that I am effective in getting things done. \\ How often do your grades or class work suffer because of the amount of time you \\ spend online? \\ PIU How often do you lose sleep due to being online? \\ How often do you choose to spend more time online over going out with others? \\ My teachers are critical of my academic performance \\ The size of the curriculum (workload) is excessive \\ Stress I believe that the amount of work assignment is too much \\ The examination questions are usually difficult \\ I can adapt to change \\ I can deal with whatever comes my way \\ Believe I can achieve goals despite obstacles \\ Resilience Under pressure I stay focused \\ I am not easily discouraged by failure \\ Think of myself as a strong person when facing challenges \\ I am pleased with what I learned in the course. \\ Perceived The learning tasks enhanced my understanding of the content. \\ learning I learned less in the course than I anticipated. \\ I learned skills that will help me in the future. \\ The course contributed to my professional development.
}

\section{References}

1. Al-Kumaim, N.H.; Alhazmi, A.K.; Mohammed, F.; Gazem, N.A.; Shabbir, M.S.; Fazea, Y. Exploring the Impact of the COVID-19 Pandemic on University Students' Learning Life: An Integrated Conceptual Motivational Model for Sustainable and Healthy Online Learning. Sustainability 2021, 13, 2546. [CrossRef]

2. Kerres, M. Against all odds: Education in Germany coping with Covid-19. Postdigit. Sci. Educ. 2020, 2, 690-694. [CrossRef] 
3. Bozkurt, A.; Sharma, R.C. Emergency Remote Teaching in a Time of Global Crisis Due to CoronaVirus Pandemic. Asian J. Distance Edu. 2020, 15, i-vi. [CrossRef]

4. Joshi, O.; Chapagain, B.; Kharel, G.; Poudyal, N.C.; Murray, B.D.; Mehmood, S. Benefits and challenges of online instruction in agriculture and natural resource education. Interact. Learn. Environ. 2020, 28, 1-12. [CrossRef]

5. Lazarevic, B.; Bentz, D. Student Perception of Stress in Online and Face-to-Face Learning: The Exploration of Stress Determinants. Am. J. Distance Educ. 2021, 35, 2-15. [CrossRef]

6. $\quad$ Ridner, S.L.; Newton, K.S.; Staten, R.R.; Crawford, T.N.; Hall, L.A. Predictors of well-being among college students. J. Am. Coll. Health 2016, 64, 116-124. [CrossRef] [PubMed]

7. Richardson, M.; Abraham, C.; Bond, R. Psychological correlates of university students' academic performance: A systematic review and meta-analysis. Psychol. Bull. 2012, 138, 353-387. [CrossRef] [PubMed]

8. Struyven, K.; Dochy, F.; Janssens, S. Students' perceptions about evaluation and assessment in higher education: A review. Assess. Eval. High Educ. 2005, 30, 325-341. [CrossRef]

9. Rovai, A.P.; Wighting, M.J.; Baker, J.D.; Grooms, D.L. Development of an instrument to measure perceived cognitive, affective, and psychomotor learning in traditional and virtual classroom higher education settings. Internet High. Educ. 2009, 12, 7-13. [CrossRef]

10. Sher, A. Assessing the relationship of student-instructor and student-student interaction to student learning and satisfaction in web-based online learning environment. Learning 2009, 8, 102-120.

11. Wighting, M. Measuring sense of community and perceived learning among alternative licensure candidates. J. Nat. Assoc. Altern. Certif. 2011, 6, 4-12.

12. Wang, J.; Liu, W.; Zhang, Y.; Xie, S.; Yang, B. Perceived stress among chinese medical students engaging in online learning in light of covid-19. Psychol. Res. Behav. Manag. 2021, 14, 549-562. [CrossRef] [PubMed]

13. Harjule, P.; Rahman, A.; Agarwal, B. A cross-sectional study of anxiety, stress, perception and mental health towards online learning of school children in India during COVID-19. J. Interdiscip. Math. 2021, 24, 411-424. [CrossRef]

14. Marengo, D.; Fabris, M.A.; Longobardi, C.; Settanni, M. Smartphone and social media use contributed to individual tendencies towards social media addiction in Italian adolescents during the COVID-19 pandemic. Addict. Behav. 2022, 126, 107204. [CrossRef]

15. Lathabhavan, R.; Padhy, P.C. Role of fear of COVID-19 in the relationship of problematic internet use and stress: A retrospective cohort study among Gen X, Y and Z. Asian J. Psychiatr. 2022, 67, 102937. [CrossRef] [PubMed]

16. Gjoneska, B.; Potenza, M.N.; Jones, J.; Corazza, O.; Hall, N.; Sales, C.M.D.; Grünblatt, E.; Martinotti, G.; Burkauskas, J.; Werling, A.M.; et al. Problematic use of the internet during the COVID-19 pandemic: Good practices and mental health recommendations. Compr. Psychiatry 2022, 112, 152279. [CrossRef]

17. Madigan, D.J.; Curran, T. Does Burnout Affect Academic Achievement? A Meta-Analysis of over 100,000 Students. Educ. Psychol. Rev. 2021, 33, 387-405. [CrossRef]

18. Chandra, Y. Online education during COVID-19: Perception of academic stress and emotional intelligence coping strategies among college students. Asian Educ. Dev. Stud. 2020, 10, 229-238. [CrossRef]

19. You, J.W.; Kang, M. The role of academic emotions in the relationship between perceived academic control and self-regulated learning in online learning. Comput. Educ. 2014, 77, 125-133. [CrossRef]

20. Schneider, M.; Preckel, F. Variables associated with achievement in higher education: A systematic review of meta-analyses. Psychol. Bull. 2017, 143, 565-600. [CrossRef]

21. Winne, P.H.; Nesbit, J.C. The psychology of academic achievement. Annu. Rev. Psychol. 2010, 61, 653-678. [CrossRef] [PubMed]

22. Dendle, C.; Baulch, J.; Pellicano, R.; Hay, M.; Lichtwark, I.; Ayoub, S.; Clarke, D.M.; Morand, E.F.; Kumar, A.; Leech, M. Medical student psychological distress and academic performance. Med. Teach. 2018, 40, 1257-1263. [CrossRef] [PubMed]

23. Kljajic, K.; Gaudreau, P.; Franche, V. An investigation of the $2 \times 2$ model of perfectionism with burnout, engagement, selfregulation, and academic achievement. Learn. Individ. Differ. 2017, 57, 103-113. [CrossRef]

24. Gabre, H.; Kumar, G. The effects of perceived stress and Facebook on accounting students' academic performance. Account. Financ. Res. 2012, 1, 87. [CrossRef]

25. Smith, K.J.; Rosenberg, D.L.; Haight, G.T. An assessment of the psychometric properties of the perceived stress scale-10 (PSS 10 ) with business and accounting students. Account. Perspect. 2014, 13, 29-59. [CrossRef]

26. Hobfoll, S.E.; Freedy, J. Conservation of resource: A general stress theory applied to burnout. In Professional Burnout: Recent Developments in Theory and Research; Schanfeli, W.B., Maslach, C., Marek, T., Eds.; Taylor \& Francis: Oxford, UK, 1993; pp. 115-129.

27. Shirom, A. Burnout in work organizations. In International Review of Industrial and Organizational Psychology; Cooper, C.L., Robertson, I., Eds.; Wiley: New York, NY, USA, 1989; pp. 25-48.

28. Young, K.S. Internet Addiction: The emergence of a new clinical disorder. Cyberpsychol. Behav. 1998, 3, 237-244. [CrossRef]

29. Bakker, A.B.; Demerouti, E. The Job Demands-Resources model: State of the art. J. Manag. Psychol. 2007, 22, 309-328. [CrossRef]

30. Rehman, U.; Shahnawaz, M.G.; Khan, N.H.; Kharshiing, K.D.; Khursheed, M.; Gupta, K.; Kashyap, D.; Uniyal, R. Depression, Anxiety and Stress Among Indians in Times of Covid-19 Lockdown. Community Ment. Health J. 2021, 57, 42-48. [CrossRef]

31. Lahiri, A.; Jha, S.S.; Acharya, R.; Dey, A.; Chakraborty, A. Has loneliness and poor resilient coping influenced the magnitude of psychological distress among apparently healthy Indian adults during the lockdown? Evidence from a rapid online nation-wide cross-sectional survey. PLoS ONE 2021, 16, e0245509. [CrossRef] 
32. Cai, H.; Xi, H.T.; Zhu, Q.; Wang, Z.; Han, L.; Liu, S.; Bai, W.; Zhao, Y.J.; Chen, L.; Ge, Z.M.; et al. Prevalence of problematic Internet use and its association with quality of life among undergraduate nursing students in the later stage of COVID-19 pandemic era in China. Am. J. Addict. 2021, 30, 585-592. [CrossRef]

33. Taufiq-Hail, G.A.-M.; Sarea, A.; Hawaldar, I.T. The Impact of Self-Efficacy on Feelings and Task Performance of Academic and Teaching Staff in Bahrain during COVID-19: Analysis by SEM and ANN. J. Open Innov. Technol. Mark. Complex. 2021, 7, 224. [CrossRef]

34. Maslach, C. Job Burnout: New Directions in Research and Intervention. Cur. Dir. Psychol. Sci. 2003, 12, 189-192. [CrossRef]

35. Maslach, C.; Jackson, S.E. The measurement of experienced burnout. J. Organ. Behav. 1981, 2, 99-113. [CrossRef]

36. Pinto, S.; Pinto, P.; Hawaldar, I.T.; Sarea, A.M. Motivation and Blockades for Entrepreneurship Among Graduates. Int. J. Sci. Technol. Res. 2019, 8, 821-828.

37. Salmela-Aro, K.; Kiuru, N.; Leskinen, E.; Nurmi, J.-E. School Burnout Inventory (SBI): Reliability and validity. Eur. J. Psychol. Assess. 2009, 25, 48-57. [CrossRef]

38. Schaufeli, W.B.; Martinez, I.M.; Pinto, A.M.; Salanova, M.; Bakker, A.B. Burnout and engagement in university students: A cross-national study. J. Cross Cult. Psychol. 2002, 33, 464-481. [CrossRef]

39. Smith, J.T.; Haight, D.T.; Emerson, D.J.; Mauldin, S.; Wood, B.G. Resilience as a coping strategy for reducing departure intentions of accounting students. Account. Edu. 2020, 29, 77-108. [CrossRef]

40. Nethravathi, P.S.R.; Bai, G.V.; Spulbar, C.; Suhan, M.; Birau, R.; Calugaru, T.; Hawaldar, I.T.; Ejaz, A. Business Intelligence Appraisal Based on Customer Behaviour Profile by Using Hobby Based Opinion Mining in India: A Case Study. Econ. Res.-Ekon. Istraž. 2020, 33, 1889-1908. [CrossRef]

41. Gokarna, V.B.; Mendon, S.; Hawaldar, I.T.; Spulbar, C.; Birau, R.; Nayak, S.; Manohar, M. Exploring the antecedents of institutional effectiveness: A case study of higher education universities in India. Econ. Res.-Ekon. Istraživanja 2021, 34, 1-21. [CrossRef]

42. Schaufeli, W.B.; Taris, T.W. The conceptualization and measurement of burnout: Common ground and worlds apart. Work Stress 2005, 19, 256-262. [CrossRef]

43. Taris, T.W. Is there a relationship between burnout and objective performance? A critical review of 16 studies. Work Stress 2006 , 20, 316-334. [CrossRef]

44. Duru, E.; Duru, S.; Balkis, M. Analysis of relationships among burnout, academic achievement, and self-regulation. J. Educ. Sci. Theory Pract. 2014, 14, 1274-1284. [CrossRef]

45. Salanova, M.; Schaufeli, W.; Martinez, I.; Breso, E. How obstacles and facilitators predict academic performance: The mediating role of study burnout and engagement. Anxiety Stress Coping 2010, 23, 53-70. [CrossRef] [PubMed]

46. Zimmermann, M.; Bledsoe, C.; Papa, A. Initial impact of the COVID-19 pandemic on college student mental health: A longitudinal examination of risk and protective factors. Psychiatry Res. 2021, 305, 114254. [CrossRef]

47. Stewart, S.L.; Toohey, A.; Celebre, A.; Poss, J.W. Abuse, mental state, and health factors pre and during the COVID-19 pandemic: A comparison among clinically referred adolescents in Ontario, Canada. Int. J. Environ. Res. Public Health 2021, 18, 10184. [CrossRef] [PubMed]

48. Vejmelka, L.; Matković, R. Online interactions and problematic internet use of croatian students during the covid-19 pandemic. Inf. J. Environ. Res. Public Health 2021, 12, 399. [CrossRef]

49. Xia, Y.; Fan, Y.; Liu, T.-H.; Ma, Z. Problematic Internet use among residential college students during the COVID-19 lockdown: A social network analysis approach. J. Behav. Addict. 2021, 10, 253-262. [CrossRef] [PubMed]

50. Duan, L.; Shao, X.; Wang, Y.; Huang, Y.; Miao, J.; Yang, X.; Zhu, G. An investigation of mental health status of children and adolescents in China during the outbreak of COVID-19. J. Affect. Disord. 2020, 275, 112-118. [CrossRef]

51. Elhai, J.D.; Yang, H.; McKay, D.; Asmundson, G.J.G. COVID-19 anxiety symptoms associated with problematic smartphone use severity in Chinese adults. J. Affect. Disord. 2020, 274, 576-582. [CrossRef]

52. Sun, Y.; Li, Y.; Bao, Y.; Meng, S.; Sun, Y.; Schumann, G.; Kosten, T.; Strang, J.; Lu, L.; Shi, J. Brief Report: Increased addictive internet and substance use behaviour during the COVID-19 pandemic in China. Am. J. Addict. 2020, 29, 268-270. [CrossRef]

53. Giuseppe, M.; Nepa, G.; Prout, T.A.; Albertini, F.; Marcelli, S.; Orrù, G.; Conversano, C. Stress, Burnout, and Resilience among Healthcare Workers during the COVID-19 Emergency: The Role of Defense Mechanisms. Int. J. Environ. Res. Public Health 2021, 18, 5258. [CrossRef]

54. Dopelt, K.; Bashkin, O.; Davidovitch, N.; Asna, N. Facing the Unknown: Healthcare Workers' Concerns, Experiences, and Burnout during the COVID-19 Pandemic-A Mixed-Methods Study in an Israeli Hospital. Sustainability 2021, 13, 9021. [CrossRef]

55. Smith, K.J.; Emerson, D.J. An analysis of the relation between resilience and reduced audit quality within the role stress paradigm. Adv. Account 2017, 37, 1-14. [CrossRef]

56. Ferradás, M.d.; Freire, C.; García-Bértoa, A.; Núñez, J.C.; Rodríguez, S. Teacher Profiles of Psychological Capital and Their Relationship with Burnout. Sustainability 2019, 11, 5096. [CrossRef]

57. Hartley, M.T. Examining the relationships between resilience, mental health, and academic persistence in undergraduate college students. J. Am. Coll. Health 2011, 59, 596-604. [CrossRef] [PubMed]

58. Ong, A.D.; Bergeman, C.S.; Bisconti, T.L.; Wallace, K.A. Psychological resilience, positive emotions, and successful adaptation to stress in later life. J. Pers. Soc. Psychol. 2006, 91, 730-749. [CrossRef] [PubMed]

59. Yeager, D.S.; Dweck, C.S. Mindsets that promote resilience: When students believe that personal characteristics can be developed. Educ. Psychol. 2012, 47, 302-314. [CrossRef] 
60. Yıldırım, M.; Solmaz, F. COVID-19 burnout, COVID-19 stress and resilience: Initial psychometric properties of COVID-19 Burnout Scale. Death Stud. 2020, 17, 1-9. [CrossRef]

61. Ishak, W.; Nikravesh, R.; Lederer, S.; Perry, R.; Ogunyemi, D.; Bernstein, C. Burnout in medical students: A systematic review. Clin. Teach. 2013, 10, 242-245. [CrossRef]

62. Smith, K.J.; Davy, J.A.; Everly, G.S. An assessment of the contribution of stress arousal to the beyond the role stress model. Adv. Account. Behav. Res. 2007, 10, 127-158.

63. Schaufeli, W.B.; Buunk, B.P. Burnout: An Overview of 25 Years of Research and Theorizing. In The Handbook of Work and Health Psychology, 2nd ed.; Schabracq, M.J., Winnubst, J.A.M., Cooper, C.L., Eds.; John Wiley \& Sons Ltd.: Hoboken, NJ, USA, $2002 ;$ pp. $383-425$.

64. Spangler, G.; Pekrun, R.; Kramer, K.; Hofmann, H. Student's emotions, psychological reactions, and coping in academic exams. Anxiety Stress Coping 2002, 15, 413-432. [CrossRef]

65. Prins, J.T.; Gazendam-Donofrio, S.M.; Tubben, B.J.; van der Heijden, F.M.; van de Wiel, H.B.; Hoekstra-Weebers, J.E. Burnout in medical residents: A review. Med. Educ. 2007, 41, 788-800. [CrossRef] [PubMed]

66. Sallie, S.N.; Ritou, V.J.E.; Bowden-Jones, H.; Voon, V. Assessing online gaming and pornography consumption patterns during COVID-19 isolation using an online survey: Highlighting distinct avenues of problematic internet behavior. Addict. Behav. 2021, 123, 107044. [CrossRef] [PubMed]

67. Pinto, S.; Pinto, P.; Darwish, S.Z.; Hawaldar, I.T. Entrepreneurial Skills and Intention of Graduate Students for Business Start-ups: A Survey from India. Int. J. Innov. Creat. Change 2020, 14, 951-970.

68. Meher, B.K.; Hawaldar, I.T.; Mohapatra, L.; Sarea, A.M. The Impact of COVID-19 on Price Volatility of Crude Oil and Natural Gas Listed on Multi Commodity Exchange of India. Int. J. Energy Econ. Policy 2020, 10, 422-431. [CrossRef]

69. Li, D. Influence of the youth's psychological capital on social anxiety during the COVID-19 pandemic outbreak: The mediating role of coping style. Iran. J. Public Health 2020, 49, 2060-2068. [CrossRef]

70. Martínez, A.M.; Del Mar Molero Jurado, M.; Del Carmen Pérez-Fuentes, M.; Martín, A.B.B.; del Mar Simón Márquez, M.; Martínez, B.M.T.; Sisto, M.; Linares, J.J.G. Self-Efficacy, Positive Future Outlook and School Burnout in Spanish Adolescents. Sustainability 2021, 13, 4575. [CrossRef]

71. Marčinko, D.; Jakovljević, M.; Jakšić, N.; Bjedov, S.; Drakulić, A.M. The importance of psychodynamic approach during COVID-19 pandemic. Psychiatr. Danub. 2020, 32, 15-21. [CrossRef]

72. Caplan, S.E. Relations among loneliness, social anxiety, and problematic internet use. Cyberpsychol. Behav. 2010, 10, $234-242$. [CrossRef] [PubMed]

73. Beard, K.W.; Wolf, E.M. Modification in the proposed diagnostic criteria for Internet addiction. Cyberpsychol. Behav. 2001, 4, 377-383. [CrossRef]

74. Dong, H.; Yang, F.; Lu, X.; Hao, W. Internet Addiction and Related Psychological Factors among Children and Adolescents in China During the Coronavirus Disease 2019 (COVID-19) Epidemic. Front. Psychiatry 2020, 11, 00751. [CrossRef] [PubMed]

75. Islam, M.S.; Sujan, M.S.H.; Tasnim, R.; Ferdous, M.Z.; Masud, J.H.B.; Kundu, S.; Mosaddek, A.S.M.; Choudhuri, M.S.K.; Kircaburun, K.; Griffiths, M.D. Problematic internet use among young and adult population in Bangladesh: Correlates with lifestyle and online activities during the COVID-19 pandemic. Addict. Behav. Rep. 2020, 12, 100311. [CrossRef] [PubMed]

76. Simsek, E.; Sali, J.B. The role of internet addiction and social media membership on university students' psychological capital. Contemp. Educ. Technol. 2014, 5, 239-256. [CrossRef]

77. Chen, I.H.; Chen, C.Y.; Pakpour, A.H.; Griffiths, M.D.; Lin, C.Y.; Li, X.D.; Tsang, H.W.H. Problematic internet-related behaviors mediate the associations between levels of internet engagement and distress among schoolchildren during COVID-19 lockdown: A longitudinal structural equation modeling study. J. Behav. Addict. 2021, 10, 135-148. [CrossRef] [PubMed]

78. Zarco-Alpuente, A.; Ciudad, V.; Ballester-Arnal, R.; Billieux, J.; Llario, M.D.G.; King, D.L.; Montoya-Castilla, I.; Samper, P.; Castro-Calvo, J. Problematic internet use prior to and during the COVID-19 pandemic. Cyberpsychology 2021, 15, 116-127. [CrossRef]

79. Jahan, I.; Hosen, I.; al Mamun, F.; Kaggwa, M.M.; Griffiths, M.D.; Mamun, M.A. How has the covid-19 pandemic impacted internet use behaviors and facilitated problematic internet use? A bangladeshi study. Psychol. Res. Behav. Manag. 2021, 14, 1127-1138. [CrossRef]

80. Xie, X.; Zhu, K.; Xue, Q.; Zhou, Y.; Liu, Q.; Hao, W.; Wan, Z.; Zhang, J.; Meng, H.; Zhu, B.; et al. Problematic Internet Use Was Associated With Psychological Problems Among University Students During COVID-19 Outbreak in China. Front. Public Health 2021, 9, 675380. [CrossRef]

81. Gerasimova, A.A.; Kholmogorova, A.B. Coping strategies, psychological well-being and problematic internet use during a pandemic. Psychol. Sci. Educ. 2021, 25, 31-40. [CrossRef]

82. Višnji'c, A.; Veličković, V.; Sokolović, D.; Stanković, M.; Mijatović, K.; Stojanović, M.; Milošević, Z.; Radulović, O. Relationship between the manner of mobile phone use and depression, anxiety, and stress in university students. Int.J. Environ. Res. Public Health 2018, 15, 697. [CrossRef]

83. Lai, C.M.; Mak, K.K.; Watanabe, H.; Jeong, J.; Kim, D.; Bahar, N.; Ramos, M.; Chen, S.H.; Cheng, C. The mediating role of Internet addiction in depression, social anxiety, and psychosocial wellbeing among adolescents in six Asian countries: A structural equation modelling approach. Public Health 2016, 129, 1224-1236. [CrossRef]

84. Sharma, A.; Sharma, R. Internet addiction and psychological well-being among college students: A cross-sectional study from Central India. J. Family. Med. Prim. Care 2018, 7, 147-151. [CrossRef] [PubMed] 
85. Fernandes, B.; Biswas, U.N.; Tan-Mansukhani, R.; Vallejo, A.; Essau, C.A. The impact of COVID-19 lockdown on internet use and escapism in adolescents. Rev. Psicol. Clin. Con Ninos Adol. 2020, 7, 59-65. [CrossRef]

86. Servidio, R.; Bartolo, M.G.; Palermiti, A.L.; Costabile, A. Fear of COVID-19, depression, anxiety, and their association with Internet addiction disorder in a sample of Italian students. J. Affect. Disor. Rep. 2021, 4, 100097. [CrossRef]

87. Alheneidi, H.; AlSumait, L.; AlSumait, D.; Smith, A.P. Loneliness and Problematic Internet Use during COVID-19 Lock-Down. Behav. Sci. 2021, 11, 5. [CrossRef] [PubMed]

88. Henseler, J.; Ringle, C.M.; Sarstedt, M. Using partial least squares path modeling in advertising research: Basic concepts and recent issues. In Handbook of Research on International Advertising; Okazaki, S., Ed.; Edward Elgar Publishing: Cheltenham, UK, 2012; p. 252. [CrossRef]

89. Bedewy, D.; Gabriel, A. Examining perceptions of academic stress and its sources among university students: The Perception of Academic Stress Scale. Health Psychol. 2015, 2, 2055102915596714. [CrossRef]

90. Connor, K.M.; Davidson, J.R.T. Development of a new Resilience scale: The Connor-Davidson Resilience scale (CD-RISC). Depress. Anxiety 2003, 18, 76-82. [CrossRef] 